\title{
A novel approach to the classification of performance on inpatient perception of hospitalization experience across the US 52 states
}

\section{Tung-Hui Jen}

Chi Mei Medical Center

Tsair-Wei Chien ( $\nabla$ smile@mail.chimei.org.tw)

ChiMei Medical Center https://orcid.org/0000-0003-1329-0679

\section{Willy Chou}

Chi Mei Medical Center

\section{Research article}

Keywords: classification of performance; choropleth; mapx-index; Google Maps; bibliometrics

Posted Date: September 9th, 2019

DOI: https://doi.org/10.21203/rs.2.14225/v1

License: (a) (i) This work is licensed under a Creative Commons Attribution 4.0 International License. Read Full License 


\section{Abstract}

Background: Medical groups identified as high-performing with different approaches have been proposed for classification of performance in the literature, but no consistently-applied approach exists for identifying high performers for the benefit of healthcare providers. Most organizations classify hospitals using domain scores and assign a letter grade (e.g., from A to F in Leapfrog Groups) to the performance level. Whether bibliometrics can be an alternative for classifying healthcare givers' performances is worthy of study. This study was performed to visualize survey results about inpatients' perceptions of hospitalization experience for the US states using bibliometrics.

Methods: We downloaded the 2014 summaries of HCAHPS (Hospital Consumer Assessment of Healthcare Providers and Services) data. Four indices of $\mathrm{h}, \mathrm{Pl}, \mathrm{Ag}$, and $\mathrm{x}$ were applied to evaluate performance based on the core domains derived from the ten domain scores for each state in the US, and then displayed online dashboards to show hospitalization satisfaction across states on Google Maps. Choropleth maps were plotted for classifying the performnces into six grades using the quantiles method.

Results: The top three states for hing quality-of-care are Louisiana, Nebraska, and South Dakota using either $\mathrm{x}$ or Ag-index to assess. The Ag-index earns the mean correlation coefficient $(=0.86)$ higher than the other three. The inpatient perception of hospitalization experience or the US states were classified and displayed on choropleth maps.

Conclusions: The classification of healthcare performance is sensitive to the domain scores, the approach in classification, and the choice of metrics. The absence of a consistently-applied approach to identify healthcare performers impedes efforts to reliably compare, select, and reward high-performing providers. The $x$-index is recommended for quantifying the performance of healthcare givers in the foreseeable future.

\section{Background}

The quality of healthcare is always an issue in hospitals, particularly in the age of patient involvement in policy and the agendas of healthcare providers [1]. There are many ways to classify quality performance on healthcare givers to the public. However, those professional indicators are unfamiliar to patients; they do not find it helpful to be provided with a static table or image format when searching for the best care [2-5].

Designating a provider as "high-performing" requires an agreed-upon definition of high performance, with standard decision rules and performance measures [6]. Regrettably, no consistent definition of what constitutes a high-performing healthcare provider or system was found [7].

The England Picker Institute Europe (EPIE) [8], Hospital Compare (HC)[9], the Hospital Consumer Assessment of Healthcare Providers and Services (HCAHPS) [10], and the Leapfrog Groups [11] are four nationwide organizations that periodically assess patient expectations of hospital healthcare, experience, 
and satisfaction, and publicly report their perceptions of their experience and level of satisfaction [1215]. However, several limitations exist when classifying the performance for each hospital or state in the US. For instance, the Leapfrog Group applies 28 evidence-based measures of patient safety to compute a numerical score through the safety score for the eligible hospital. The numerical score is then converted into one of five letter grades. "A" represents the best safety grade, followed in order by " $B$," "C," " $D$," and " $F$ " [16]. In 2018, letter-grade cutoff points were set for standard deviations at $\geq 0.6, \geq 0, \geq-1.5, \geq-3.0$, and $<-3.0$. Any hospital missing more than seven process measures, or more than five outcome measures would not be graded [16].

Similar to the study [6] adopting an all-or-nothing approach to defining high performance, only 58 medical groups reporting all selected measures across the four domains were selected from the total 240 medical groups in the database.

In the bibliometric analysis, an author individual research achievement is solely on the core publications at $h$, for example, using $h$-index [19] to interpret. The $h$-index is defined as the maximum value of $h$ such that the given author has published $h$ papers that have each been cited at least $h$ times. As such, the index is designed to improve upon simpler measures instead of the total number of citations or publications applied to evaluate the achievements in academics. We thus have the motivation to use the metrics for classifying the performance of hospitals or the US states we did in this study.

The study aims to visualize survey results about inpatients' perceptions of hospitalization experience for the US states using bibliometrics to display. The tasks include (1) calculating metrics and determining the core domains on inpatient perception of hospitalization experience for each state in the US; (2) understanding the relations between types of metrics used in this study; (3) classifying the grades for each state using choropleth maps; and (4) highlighting the characteristics of the US states by using the metrics and the Kano model [20].

\section{Methods}

\section{Study Data}

We downloaded data (Summary Analysis of HCAHPS survey results in 2014) on discharges of inpatient perceptions of their hospitalization experience across all 50 US states, Washington, DC, and the territory of the United States Virgin Islands, for a total of 52 areas, at the HCAHPS website [8]. The freely available spreadsheet there includes 10 dimension scores (range: 0-100 [higher is better]) consisting of the following: (1) Communication with Nurses, (2) Communication with Doctors, (3) Responsiveness of Hospital Staff, (4) Pain Management, (5) Communication about Medicines, (6) Cleanliness of the Hospital Environment, (7) Quietness of the Hospital Environment, (8) Discharge Information, (9) Overall Hospital Rating, and (10) Recommendation of the Hospital, see Additional file 1 and 2.

\section{Task 1: Calculating metrics and determining the core domains}


Four metrics [18,20-22] below were applied to calculate performances and determine the core domains based on the ten dimension scores mentioned in the previous subsection. We define these metrics like the following: [Due to technical limitations, this equation is only available as a download in the supplemental files section], where ci is the citations at the ith publications, $g$ is determined at the squared $g$ not greater than the total citations at the gth publications, $\mathrm{C}(\mathrm{P} \pi)$ is the total citation till the [Due to technical limitations, this equation is only available as a download in the supplemental files section] publications. All the citations for each publication have been sorted at the first step by descending order.

For instance, on the $x$-index applied to the inpatient perceptions (ci) across the ten domains, we sort the domain scores for a specific state first, and then determine the number of domains at I, the responding ci, and the core at $i$. The greater is the metric, the higher is the performance of the state. It is worth noting that the domain scores have been divided by a value (e.g., 10 or 8 ) to meet the number of domains in this study. Otherwise, the $\mathrm{h}$ and $\mathrm{g}$ indexes would be at ten because $\mathrm{h}$ and $\mathrm{g}$ are always smaller than .or the $\mathrm{Ag}$ (i.e., $10<$ the least domain score in the dataset).

Task 2: Understanding the relations between types of metrics

The four metrics, along with the mean score for all states, were assessed by their correlation coefficients. From this, we can determine which metric earns the more or less mean coefficient. Two scenarios were manipulated by transforming domain scores by dividing 10 and 8 , respectively.

\section{Task 3: Classifying the grades for each state using choropleth maps to display}

We created choropleth maps [23-25] to display the grades for each state. The quantiles method was used for classifying the grades to place an equal number of observations in each class. The problem with quantiles is that value legends with classes have very different numerical ranges (e.g., 1-4, 5-9, 10-250; the last class is huge): a situation that is very undesirable. The advantage of using quantiles is that they are suitable for computing Gini coefficient [26] and analysis of variance (ANOVA), owing to the almost equal number of sizes among classes.

\section{Task 4: Highlighting the US states by the metrics using the Kano model}

The Kano model is used for product development and customer satisfaction. It was developed in 1984 by Professor Noriaki Kano [1], and classifies products or items into four major categories: the must-be quality, the one-dimensional quality, the attractive quality, and the indifferent quality, on a diagram based on the satisfaction perceived by customers on Axis $Y$ and the effort achieved by providers on Axis $X$. The first three categories have been transformed into various terms such as "delighters/exciters," "satisfiers," "dissatisfiers," but all refer to Kano's original articles.

In this study, we plot a Kano diagram to present the states on a dashboard displayed on Google Maps. The number of domains is on the $\mathrm{X}$-axis and the scores at the number of core domains on the $\mathrm{Y}$-axis. The bubbles are sized by the metrics and colored by the characteristics classified by the Kano mod 


\section{Results}

\section{Task 1: Calculating metrics and determining the core domains}

We present the $x$-index and the number of core domains in Table 1. The top three states are South Dakota ( $=80.3$ ), Louisiana $(=80)$, and Nebraska $(=80)$, using the total (or the mean) to compare. If $x$-index is applied, Louisiana ( = 7.9) ranks first and followed by South Dakota $(=7.8)$, and Nebraska (=7.8). All of them have an identical number of core domains ( =9). The domain of Overall Hospital Rating on item 9 is redundant and therefore excluded from the core domain by many states.

\section{Task 2: Understanding the relations between types of metrics}

We were curious about whether any difference exists if disparate metrics are applied. The original summation (or average) score and the Ag own the highest mean coefficient ( $=0.86$ ), followed by $\mathrm{x}$-index $(=0.79)$ and $\mathrm{PI}(=0.77)$. The h-index has a lower coefficient $(=0.67)$; see Table 1. It is worth noting that the $x$-index remains identical regardless of whether the domain scores were divided by 10 or 8 . This is because the linear transformation for domain score (ci) do not affect the ranking $x$-index, which is determined by the maximum product of $i$ and ci [Due to technical limitations, this equation is only available as a download in the supplemental files section] using the rectangle area to evaluate.

\section{Task 3: Classifying the grades for each state using choropleth maps to display}

Choropleth maps are shown in Figures 1 and 3 using $x$ and Ag-index to display, respectively. The top three states are identical in these two maps, but the difference in order exists, indicating that the classification approach is sensitive to the results of the performance assessment [6]. Six grades on the inpatient perception of hospitalization for the US states were classified and displayed on choropleth maps; see the colors in Figures 1 and 2.

\section{Task 4: Highlighting the US states by the metrics using the Kano model}

The number of core domains is ranged within 8 and 10 if $x$-index is applied, different from the Ag in a range between 6 and 7, see Figure 3 and 4 . Due to g similar to h-index at ci $=h$, all bubbles called the onedimensional quality in Ag-index are present between the two blue limit lines in Figure 4. In contrast, some are classified as the productive quality in red bubbles using $x$-index to display in Figure 3.

If the domain scores are transformed by dividing the value of 8 instead of by 10 in Figure 3 , the rankings for $x$-index across states are retained, but the dispersion is changed, and more states in green are located at the top in Figure 5 because the scores have been augmented by dividing by 8 instead of 10, as in Figure 3.

\section{Discussion}


We observed that the top three states with higher quality-of-care are Louisiana, Nebraska, and South Dakota using either $x$ or Ag-index to assess. The Ag-index earns the mean correlation coefficient $(=0.86)$ higher than the other three metrics. Six grades on the inpatient perception of hospitalization were classified for the US states.

\section{1 What this study contributes to current knowledge}

We applied the metrics to rate inpatient perceptions of hospitalization experience in the US states. The principle of the bibliometric analysis disregards redundant domains and the excess scores for taking into account, which is a simple and easy way to compute metrics and categorize the classes, particularly using the Kano model for classification, which is never seen in past articles.

The quantiles methods or others [27, 28], such as the equal interval method and natural breaks (e.g., using an algorithm as k-mean [29]) can be properly used for classifying classes for entities. We particularly highlight the vital few classes labeled by the number from 1 to 3 on choropleth maps (see Figures 2 and 4), which is one of the features in this study.

Another feature is the Kano model applied to classify the entities. The reason there are no such states at the top is that the transformed domain scores (i.e., divided by 10) are less the score in Figure 3 than that score (i.e., divided by 8) in Figure 5. For instance, Louisiana in Figure 1 has the highest x-index at 7.88, but the domain score (ci) is 6.9 less than the number of $\mathrm{x}$-core at 9 . Another example is the District of Columbia, with $x$-index $=6.82$, domain score at 5.8 less than the core at 6 in Figure 4. Interested readers are invited to scan the QR-code in Figures to see the details about any state. The dashboard on Google Maps is another feature that allows the public to easily understand and quickly select the high-performing states.

\subsection{Strengths of this study}

We recommend using the $x$-index to evaluate the quality-of-care for hospitals or the US states. The reason is not only the feature of invariance in Table 2, but also the suitability of three main classifications displayed in the Kano diagram. Although the Ag has higher discrimination power than the $\mathrm{h}$ and $\mathrm{g}$-index [30], the $x$-index also owns the discrimination power for ranking institutional-level research achievements.

On the other hand, we usually discard hospitals with missing items in classifications of performance [16] or like the study [6] only including 58 medical groups reporting all selected measures across the four domains. We mimic the bibliometric analysis considering the core publications (or domains in the current study), like the individual-level metrics ( $h, g, P I$, or $x$ ) that can evaluate any one with a variety of publications and citations in the past. Accordingly, many hospitals (or states) can be assessed together on a diagram, see Figures in this study.

Furthermore, many examples of disparities in health outcomes across areas, such as dengue outbreaks [31,32], disease hotspots [33], and the Global Health Observatory (GHO) maps on major health topics [34], 
have been presented using choropleth maps [23-25] to display. Our representation in Figures 1 and 2 on Google Maps is unique and innovative and has no precedent in the literature.

\subsection{Limitations and suggestions}

Despite the findings shown above, several potential limitations require further research efforts. First, the sample for this study only comprised HCAHPS survey results from 2014. As such, the top three states (Louisiana, Nebraska, and South Dakota) with higher quality-of-care cannot be generalized to other years or areas.

Second, there might be some biases when downloading HCAHPS survey results from the website. For example, it is worth further examining why the domain score for item 9 of Overall Hospital Rating in Tabel 1 is so much lower than other domains.

Third, we recommend using the Kano diagram to classify entities. There is no software [35] that can be commonly used for ordinary researchers. Our technique of plotting a Kano diagram in MS Excel for visualizing and classifying the characteristics of entities needs to be explained in detail in another future article.

Fourth, although the $\mathrm{x}$-index is recommended for hospital evaluations in the classification of performance according to Table 2, other indices or approaches, such as relative thresholds or absolute values of performance, are worthy of discussions and further study.

Finally, numerous classification methods used for displaying legends on choropleth maps have been proposed before $[27,28]$. We applied the quantiles method to classify six grades for US states (see Figures 1 and 2), which is also worth discussing the merits and disadvantages used for displaying choropleth maps in the future.

\section{List Of Abbreviation}

API: application programming interface

CC: correlation coefficient

EPIE:The England Picker Institute Europe

HCAHPS: Hospital Consumer Assessment of Healthcare Providers and Services

VBA: visual basic for application

\section{Declarations}

Ethics approval and consent to participate 
All the data used in this study were extracted from HCAHPS, which means the study does not require ethical approval according to the regulations promulgated by the Taiwan Ministry of Health and Welfare.

Consent to publish

Not applicable.

Availability of data and materials

The datasets generated and analyzed during the current study are available in the Additional file 2.

Competing interests

The authors declare that they have no competing interests.

\section{Funding}

There are no sources of funding to be declared.

\section{Authors' Contributions}

TH conceived and designed the study, TH, and TW interpreted the data, and WC monitored the process and the manuscript. TW drafted the manuscript. All authors read the manuscript and approved the final manuscript.

\section{Acknowledgments}

We thank Enago (www.enago.tw) for the English language review of this manuscript.

\section{Reference}

1. Kaltoft MK, Nielsen JB, Salkeld G, Dowie J. Increasing user involvement in health care and health research simultaneously: a proto-protocol for "person-as-researcher" and online decision support tools. JMIR Res Protoc 2014 (Nov 25); 3(4):e61.

2. Dhalla IA, Tepper J.Improving the quality of health care in Canada. CMAJ. 2018 Oct 1;190(39):E1162E1167.

3. Emmert M, Schlesinger M.Hospital Quality Reporting in the United States: Does Report Card Design and Incorporation of Patient Narrative Comments Affect Hospital Choice?Health Serv Res. 2017 Jun;52(3):933-958..

4. Lee MK, Yost KJ, Pierson KE, Blackmon SH.Patient-reported outcome domains for the esophageal CONDUIT report card: a prospective trial to establish domains. Health Qual Life Outcomes. 2018 Oct 10;16(1):197.

5. Ahluwalia SC, Damberg CL, Haas A, Shekelle PG.How are medical groups identified as highperforming? The effect of different approaches to classification of performance.BMC Health Serv 
Res. 2019 Jul 18;19(1):500.

6. Ryan A, Sutton M, Doran T. Does winning a pay-for-performance bonus improve subsequent quality performance? Evidence from the hospital quality incentive demonstration. Health Serv Res. 2014;49(2):568-87.

7. EPIE. Patient survey report - adult inpatients. Picker Institute Europe, Oxford. 2018/1/11 retrieved at http://www.pickereurope.org/

8. Hospital Compare. 2018/11/11 retrieved at https://www.medicare.gov/hospitalcompare/search.html

9. HCAHPS. Hospital Consumer Assessment of Healthcare Providers and Services. 2018/11/11 retrieved at http://www.hcahpsonline.org/globalassets/hcahps/summary-analyses/results/201710_summary-analyses_states-results.pdf

10. Austin JM, D’Andrea G, Birkmeyer JD, Leape LL, Milstein A, Pronovost PJ, Romano PS, Singer SJ, Vogus TJ, Wachter RM.Safety in numbers: the development of Leapfrog's composite patient safety score for U.S. hospitals. J Patient Saf. 2014 Mar;10(1):64-71.

11. Jenkinson C, Coulter A, Bruster S, Richards N, Chandola T. Patients' experiences and satisfaction with health care: results of a questionnaire study of specific aspects of care. Qual Saf Health Care 2002; 11(4):335-9.

12. Goldstein E, Farquhar M, Crofton C, Darby C, Garfinkel S. Measuring hospitalcare from the patients' perspective: an overview of the CAHPS hsopital Surveydevelopment process. Health Serv Res 2005; 40, 1977-95.

13. Meddings J, Smith SN, Hofer TP, Rogers MAM, Petersen L, McMahon LF Jr.Mixed messages to consumers from Medicare: Hospital Compare grades versus value-based payment penalty.Am J Manag Care. 2018 Dec 1;24(12):e399-e403.

14. History of Leapfrog Group.http://www.leapfroggroup.org/about/history Accessed October 22, 2018.

15. Explanation of Hospital Safety Grades for Leapfrog Group. http://www.hospitalsafetygrade.org/media/file/ExplanationofSafetyGrades_Fall2018_PublicWeb.pdf Accessed October 22, 2018.

16. Institute of Medicine: crossing the quality chasm: a new health system for the 21 st century. Washington, DC; 2001.

17. Nolan T, Berwick DM. All-or-none measurement raises the bar on performance. JAMA. 2006;295(10):1168-70.

18. Hirsch JE. An index to quantify an individual's scientific research output. Proc Natl Acad Sci USA 2005;102:16569-72.

19. Kano N, Seraku N, Takahashi F, Tsuji S. Attractive Quality and Must-Be Quality. Journal of the Japanese Society for Quality Control 1984; 41: 39-48.

20. Egghe L, Rousseau R, Van Hooydonk G. Methods for accrediting publications to authors or countries: Consequences for evaluation studies. J Am Soc Inform Sci. 2000; 51(2): 145-157. 
21. Fenner T, Harris M, Levene M, Bar-llan J. A novel bibliometric index with a simple geometric interpretation. PLoS One. 2018;13(7):e0200098

22. Vinkler P.The $\pi$-index: a new indicator for assessing scientific impact.Journal of Information Science 2009;35 (5):602-612

23. Cromley RG, Cromley EK. Choropleth map legend design for visualizing community health disparities. Int J Health Geogr. 2009; 8:52.

24. Barcelona Field Studies Centre. Choropleth Map with Proportional Symbols. 2019/4/4 available at https://geographyfieldwork.com/DataPresentationMappingTechniques.htm

25. Cromley RG, Ye Y. Ogive-based legends for choropleth mapping. Cartogr Geogr Inform Sci.2006;33:257-268. doi: 10.1559/152304006779500650.

26. Gini C. Concentration and dependency ratios (in Italian). English translation in Rivista di Politica Economica 1909; 87 (1997), 769-789.

27. Richards TB, Berkowitz Z, Thomas CC, Foster SL, Gardner A, King JB, Ledford K, Royalty J.Choropleth map design for cancer incidence, part 1.Prev Chronic Dis. 2010 Jan;7(1):A23.

28. Richards TB, Berkowitz Z, Thomas CC, Foster SL, Gardner A, King JB, Ledford K, Royalty J.Choropleth map design for cancer incidence, part 2.Prev Chronic Dis. 2010 Jan;7(1):A24.

29. Hartigan JA, Wong MA. A k-Means Clustering Algorithm. Journal of the Royal Statistical Society 1979; Series C. 28 (1): 100-108.

30. Huang MH, Chi PS. A comparative analysis of the application of h-index, g-index, and A-index in institutional-level research evaluation. Journal of Library and Information Studies 2010; 8(2):1-10.

31. Chen WJ. Dengue outbreaks and the geographic distribution of dengue vectors in Taiwan: A 20-year epidemiological analysis.Biomed J 2018;41(5):283-289.

32. Lai WT, Chen $\mathrm{CH}$, Hung H, Chen RB, Shete $\mathrm{S}$, Wu CC.Recognizing spatial and temporal clustering patterns of dengue outbreaks in Taiwan.BMC Infect Dis. 2018;18(1):256.

33. Soetens L, Hahné S,Wallinga J. Dot map cartograms for detection of infectious disease outbreaks: an application to Q fever, the Netherlands and pertussis, Germany.Euro Surveill 2017;22(26): pii: 30562.

34. WHO. Global Health Observatory Map Gallery. 2019/4/1 avaiable at https://www.who.int/gho/map_gallery/en/

35. Atlason RS, Giacalone D. Rapid computation and visualization of data from Kano surveys in R.BMC Res Notes. 2018 Nov 28;11(1):839.

\section{Tables}

Table 1.a The scores of inpatient satisfaction survey in 2014 for each State in the US 


\begin{tabular}{lcccccccccccc}
\hline State & 1 & 2 & 3 & 4 & 5 & 6 & 7 & 8 & 9 & 10 & Cik Core $x$ & \multicolumn{3}{c}{ Mean Rank } \\
\hline AK & 76797166717356885069 & 6.6 & 87.3 & 73.0 & 42 \\
\hline AL & 81866973667272865272 & 6.6 & 97.7 & 77.3 & 12 \\
\hline AR & 80846870647367835171 & 6.4 & 97.6 & 75.5 & 26 \\
\hline AZ & 77786670647057865170 & 5.7 & 97.2 & 72.8 & 43 \\
\hline CA & 75786269617051854968 & 4.9 & 10 & 7 & 71.0 & 46 \\
\hline CO & 79817071677565885574 & 6.5 & 97.7 & 75.3 & 28 \\
\hline CT & 79806471647152875168 & 6.4 & 87.2 & 73.5 & 39 \\
\hline DC & 70775264566054804158 & 5.2 & 96.8 & 65.8 & 51 \\
\hline DE & 79796769637055875169 & 5.1 & 107.1 & 73.5 & 39 \\
\hline FL & 767763686170598449675.9 & 97.3 & 71.0 & 46 \\
\hline GA & 79836671647268855171 & 6.4 & 97.6 & 74.8 & 33 \\
\hline HI & 81837072667661845370 & 6.1 & 97.4 & 76.5 & 17 \\
\hline IA & 82847273677966885576 & 6.6 & 97.7 & 77.8 & 6 \\
\hline ID & 818475737077638957735.7 & 107.6 & 78.3 & 4 \\
\hline IL & 80816872647461875271 & 6.1 & 97.4 & 75.3 & 28 \\
\hline IN & 82837172657662885575 & 6.2 & 97.5 & 77.0 & 14 \\
\hline KS & 81857273667667875776 & 6.6 & 97.7 & 77.8 & 6 \\
\hline KY & 81847072667566875373 & 6.6 & 97.7 & 76.8 & 15 \\
\hline LA & 84877376697674865876 & 6.9 & 97.9 & 80.0 & 2 \\
\hline MA & 80816671647253895370 & 5.3 & 107.3 & 74.5 & 36 \\
\hline MD & 76796068606657864865 & 5.7 & 97.2 & 70.8 & 48 \\
\hline ME & 83837173698059895775 & 5.7 & 107.6 & 77.5 & 9 \\
\hline MI & 81817172657461885372 & 6.1 & 97.4 & 76.3 & 19 \\
\hline MN & 82847471677867885675 & 6.7 & 97.8 & 77.8 & 6 \\
\hline MO & 80826870657364875371 & 6.4 & 97.6 & 75.0 & 31 \\
\hline MS & 81867073667472855171 & 6.6 & 97.7 & 77.5 & 9 \\
\hline
\end{tabular}

Table 1.b The scores of inpatient satisfaction survey in 2014 for each State in the US 


\begin{tabular}{lcccccccccccc}
\hline State & 1 & 2 & 3 & 4 & 5 & 6 & 7 & 8 & 9 & 10 Cik Core x & \multicolumn{3}{c}{ Mean Rank } \\
\hline MT & 79847272657361855268 & 6.1 & 97.4 & 76.8 & 15 \\
\hline NC & 81836871667264875271 & 6.4 & 97.6 & 75.8 & 23 \\
\hline ND & 81827373617365815269 & 6.1 & 97.4 & 77.3 & 12 \\
\hline NE & 83867774688069885877 & 6.8 & 97.8 & 80.0 & 2 \\
\hline NH & 81817172677657895473 & 5.4 & 107.4 & 76.3 & 19 \\
\hline NJ & 77786169606853834764 & 6 & 86.9 & 71.3 & 45 \\
\hline NM & 76786768647162844866 & 6.2 & 97.5 & 72.3 & 44 \\
\hline NV & 73756066606954844866 & 5.4 & 9 & 7 & 68.5 & 50 \\
\hline NY & 76776267607052854764 & 6 & 86.9 & 70.5 & 49 \\
\hline OH & 81817072657560885373 & 6 & 97.4 & 76.0 & 21 \\
\hline OK & 808572736674708653736.6 & 97.7 & 77.5 & 9 \\
\hline OR & 79816970657456885271 & 6.5 & 87.2 & 74.8 & 33 \\
\hline PA & 80806771637355875170 & 5.1 & 107.1 & 74.5 & 36 \\
\hline RI & 80816772637255875270 & 5.2 & 107.2 & 75.0 & 31 \\
\hline SC & 80836870667268865372 & 6.6 & 97.7 & 75.3 & 28 \\
\hline SD & 83867874687870885578 & 6.8 & 97.8 & 80.3 & 1 \\
\hline TN & 80836972657367865271 & 6.5 & 97.7 & 76.0 & 21 \\
\hline TX & 80837073667569865374 & 6.6 & 97.7 & 76.5 & 17 \\
\hline UT & 80836971647464905876 & 5.8 & 107.6 & 75.8 & 23 \\
\hline VA & 79816570657261885170 & 6.1 & 97.4 & 73.8 & 38 \\
\hline VT & 80817269667753895472 & 5.3 & 107.3 & 75.5 & 26 \\
\hline WA & 78806669637356885170 & 5.1 & 107.1 & 73.3 & 41 \\
\hline WI & 83837373697965905677 & 6.5 & 97.7 & 78.0 & 5 \\
\hline WV & 79826870657458875067 & 5.8 & 97.2 & 74.8 & 33 \\
\hline WY & 78817371677464895268 & 6.4 & 97.6 & 75.8 & 23 \\
\hline
\end{tabular}

Table 2 Correlation among metrics

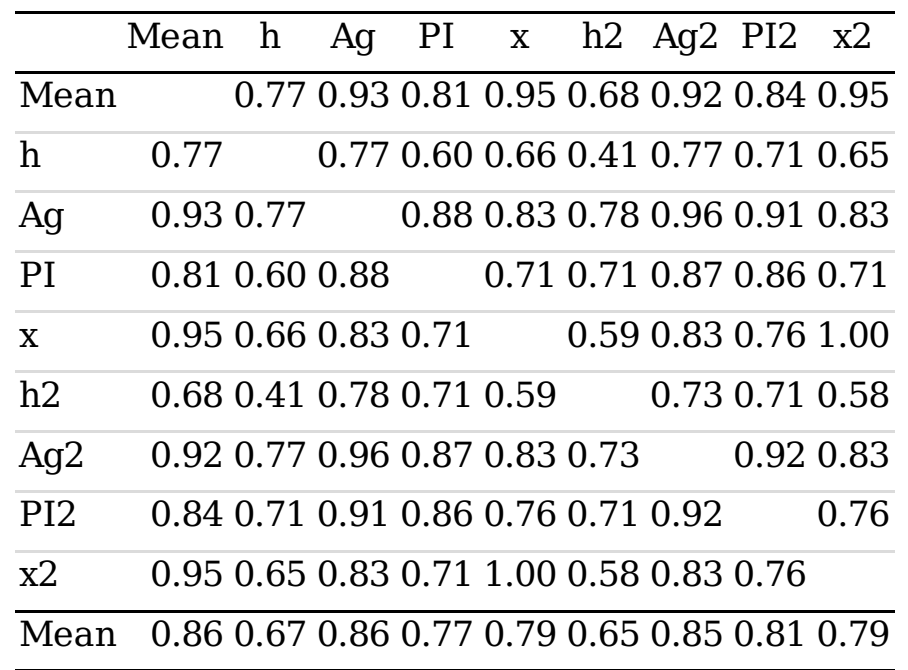


Note. Two datasets divided by 10 and 8 were transformed

\section{Conclusions}

Conclusions

The classification of healthcare performance is sensitive to the domain scores(e.g., composite or summation score), the approach in classification(e.g., Kano model), and the choice of metrics(e.g.,xindex). The absence of a consistently-applied approach to identify healthcare performers impedes efforts to reliably compare, select, and reward high-performing providers. The Kano model and the $x$-index is recommended for quantifying the performance of healthcare givers in the foreseeable future.

Figures
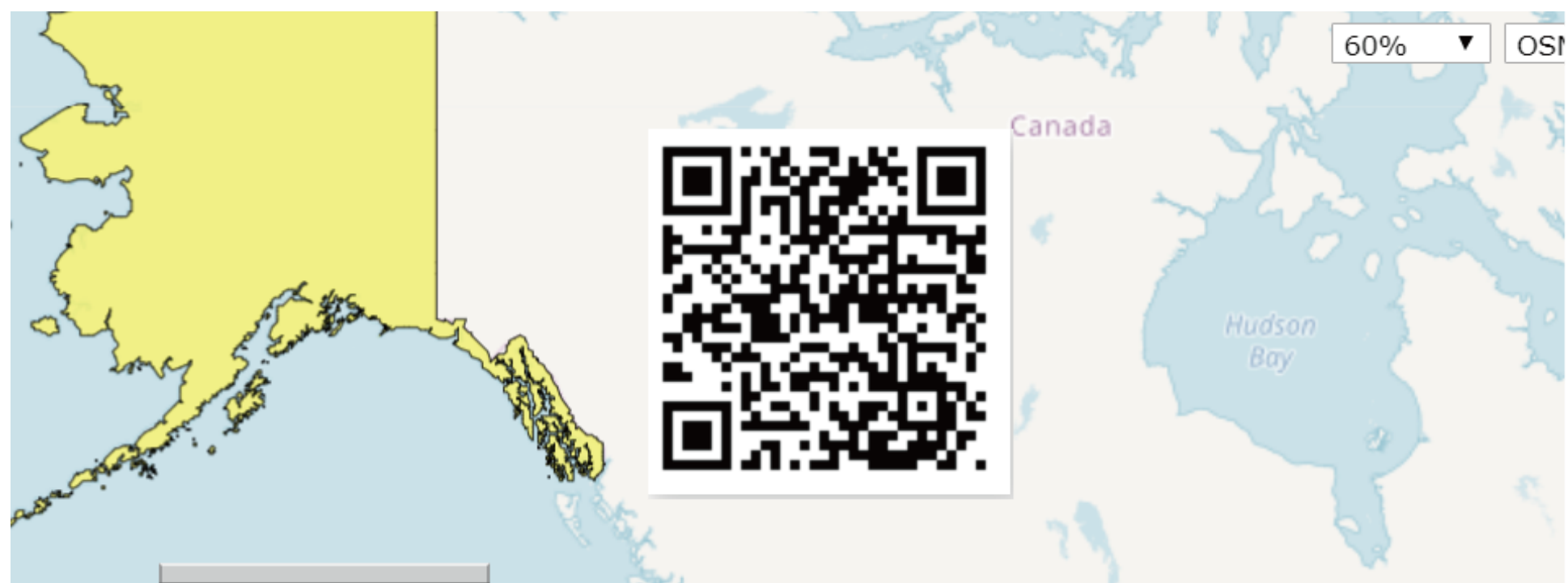

\begin{tabular}{|l|}
\hline$x-i n d e x \%: n$ \\
Gini=0.22 \\
$<7.16$ F:20.47\%,(11). \\
\hline$<7.35-E: 37.74 \%,(\underline{9})$ \\
\hline$<7.47-D: 53.41 \%,(\underline{8})$ \\
\hline$<7.65-C: 75.47 \%,(11)$. \\
\hline$<7.71-B: 91.74 \%,(\underline{8})$. \\
$>=7.7 \overline{7} A: 100 \%,(\underline{4})$. \\
\hline Refresh \\
\hline
\end{tabular}

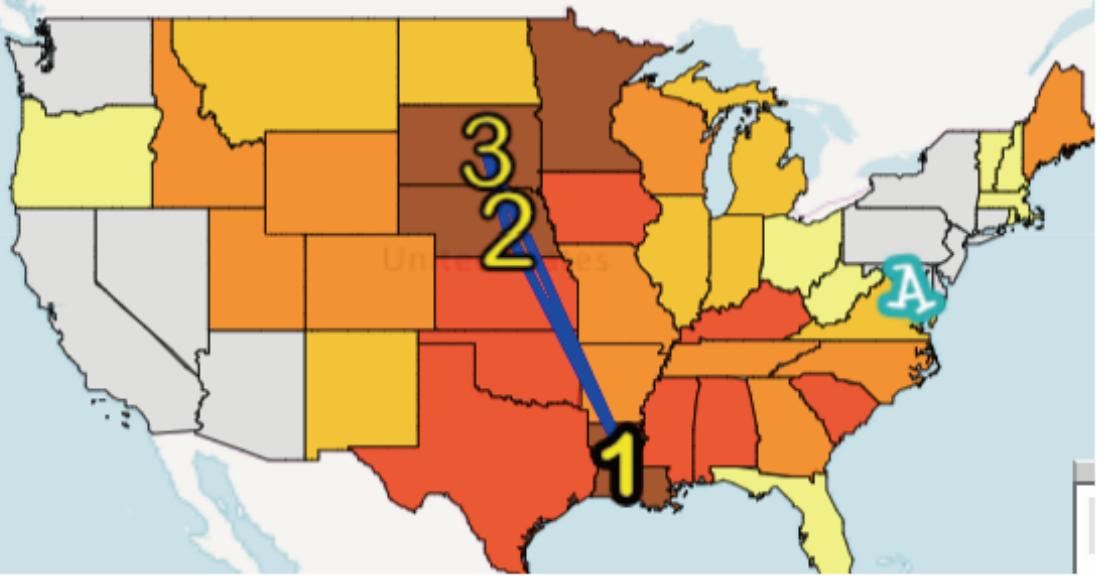

Figure 1

Inpatient satisfaction for the US states in 2014 using $x$-index to display 


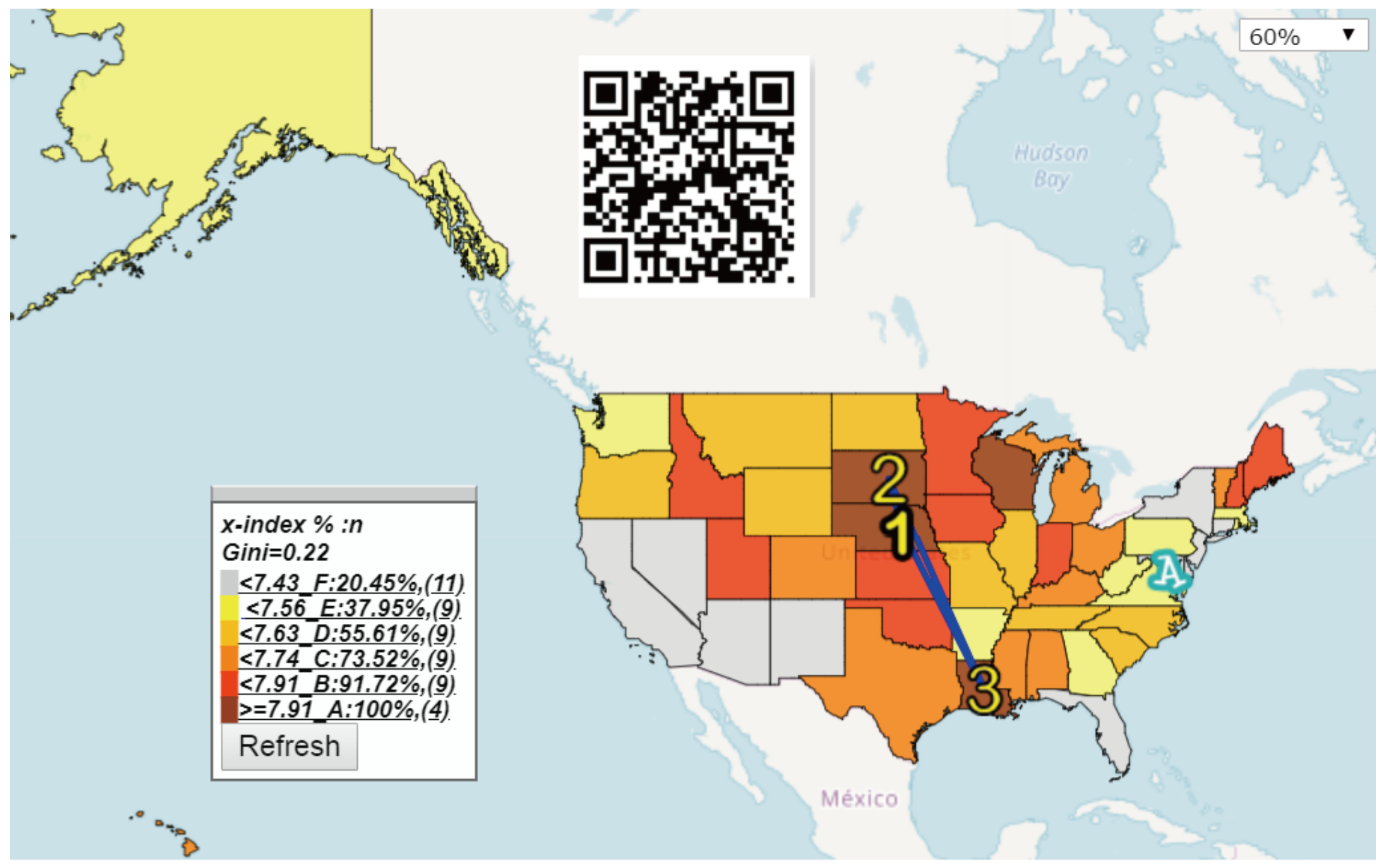

Figure 2

Inpatient satisfaction for US states in 2014 using Ag-index to display 


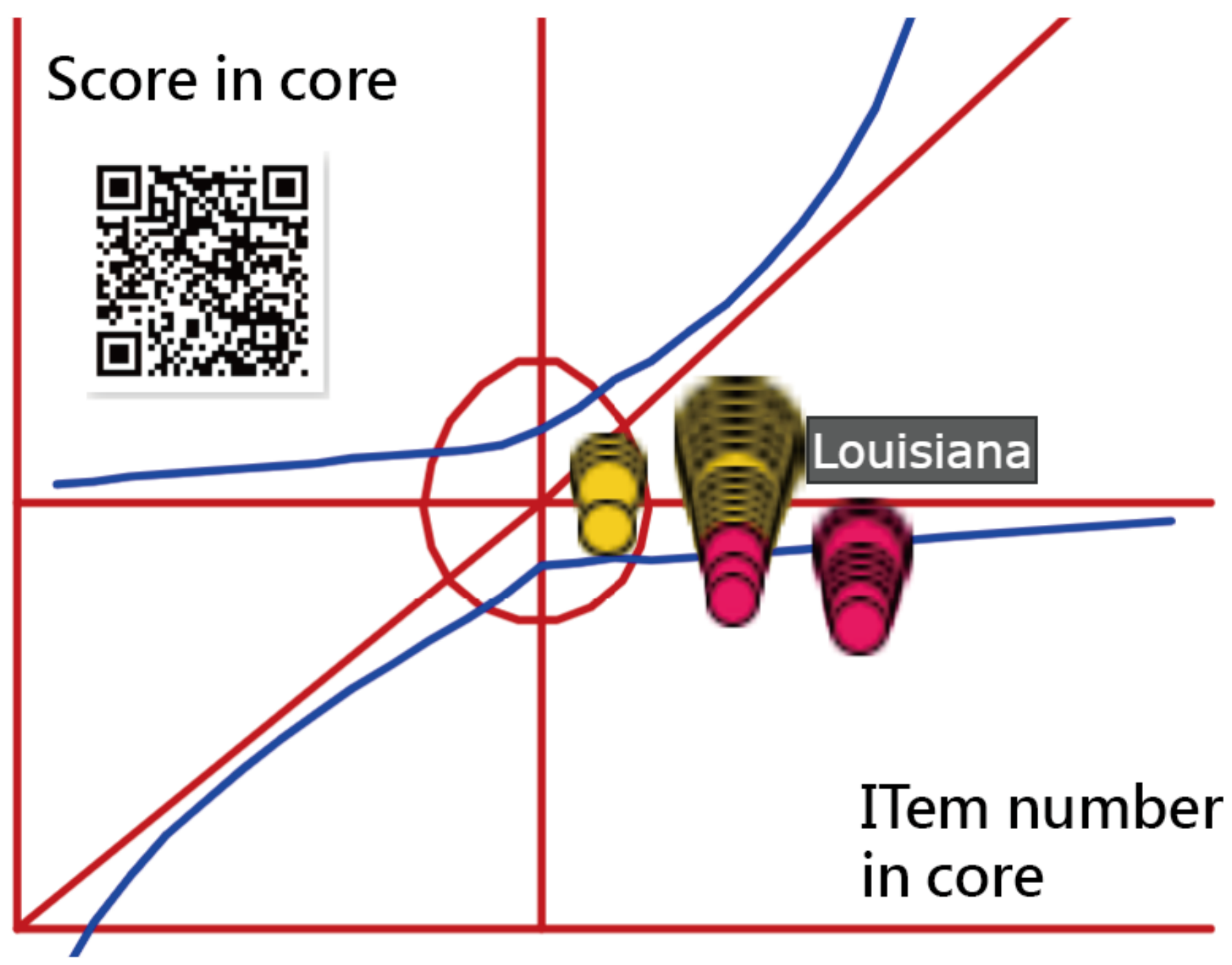

Figure 3

Inpatient satisfaction for the US states in 2014 dispersed by $\mathrm{x}$-index to display when scores were divided by 10 


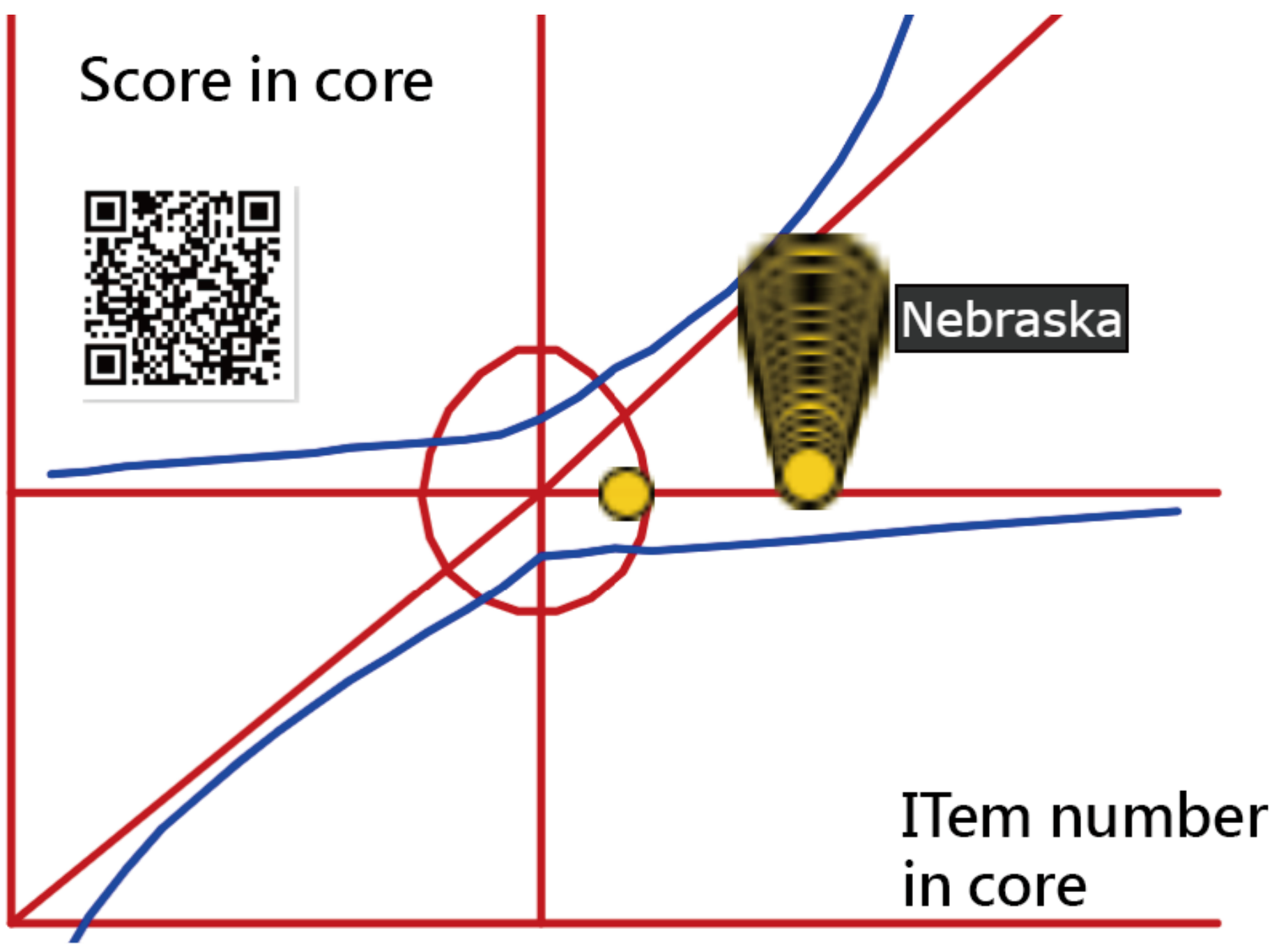

Figure 4

Inpatient satisfaction for the US states in 2014 dispersed by Ag-index to display 


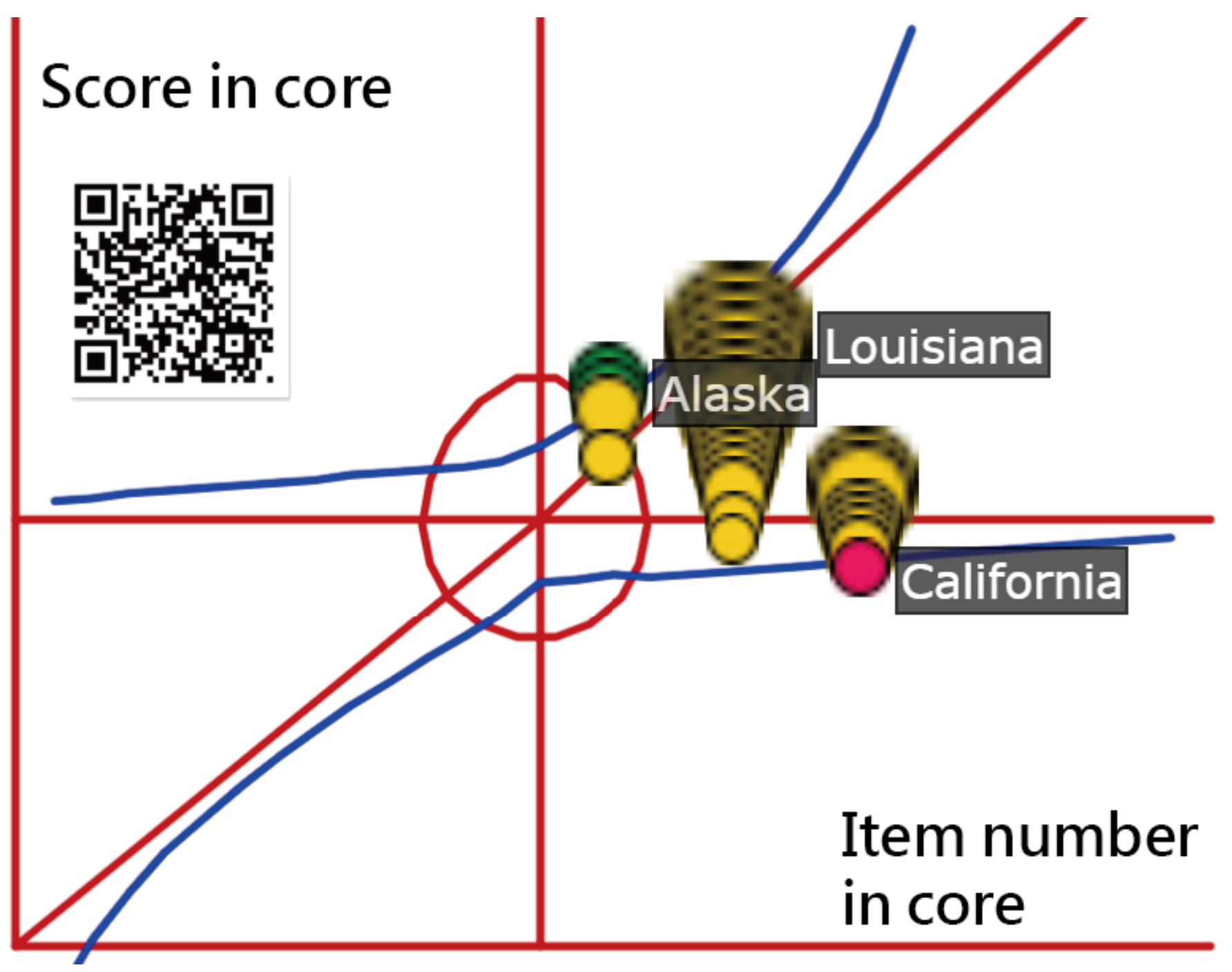

Figure 5

Inpatient satisfaction for the US states in 2014 dispersed by $\mathrm{x}$-index to display when scores were divided by 8

\section{Supplementary Files}

This is a list of supplementary files associated with this preprint. Click to download.

- eq3.jpg

- dataset22.xIsx

- questions.pdf

- eq1.jpg

- eq2.jpg 